University for Business and Technology in Kosovo

UBT Knowledge Center

UBT International Conference

2012 UBT International Conference

Nov 2nd, 9:00 AM - Nov 3rd, 5:00 PM

\title{
Advancement Of The Plastering Machine
}

Bujar Ademi

Peter Kopacek

Vienna University of Technology, kopacek@ihrt.tuwien.ac.at

Follow this and additional works at: https://knowledgecenter.ubt-uni.net/conference

Part of the Computer Sciences Commons, and the Engineering Commons

\section{Recommended Citation}

Ademi, Bujar and Kopacek, Peter, "Advancement Of The Plastering Machine" (2012). UBT International Conference. 64.

https://knowledgecenter.ubt-uni.net/conference/2012/all-events/64

This Event is brought to you for free and open access by the Publication and Journals at UBT Knowledge Center. It has been accepted for inclusion in UBT International Conference by an authorized administrator of UBT Knowledge Center. For more information, please contact knowledge.center@ubt-uni.net. 


\title{
ADVANCEMENT OF THE PLASTERING MACHINE
}

\author{
Bujar Ademi, Prof. Dr.Peter Kopacek
}

ABSTRACT. Automation of water flow at plastering machines is a solution which serves the process of plastering, to adhere international standards.Automation of water flow by taking signals from the condition of the material depending on humidity. So its output is used to influence the increase or decrease of the amount of water flow in the valve.Water flow automation is a system which consists of several components in which the already, develop different processes.

To realese the feedback we need a sensor which is built by piezoelemnt in which we have the phenomenon of the frequency. With which we have to create a variable signal at the entrance of electronic board. This signal varies depending on the moisture condition to the material of the exit of machine.

Electronic board which is part of an intelligent system where we have 6 incoming signals and 4 signals at its output.

We have an actuator which depending on the orders it receives from electronic board in valve reacts and works to increase and decrease the amount of water that flows.

We have a float 1,0,2 (auto, 0, manual) which serves to orient the system in manual or automatic system.

Manual system is realized through one potentiometer, while automatic system is implemented by using the sensor. So it comes to obtaining information on the move again while the system operates automatically.

Keywords: Plastering machine, Water flow control, Automation of plastering machine, Putzmaschine,

\section{- INTRODUCTION}

Plastering is widely used as a finishing technology for both interior and exterior walls made from bricks, concrete or timber. While plastering of exterior walls provides heat insulation, sound absorption and protection against air pollution and weather, the application of plaster to interior walls improves the indoor climate by humidity regulation and serves the purpose of compensating inevitable tolerances of the brickwork, thus providing a clean, level surface for further finishing tasks. Special plaster material can also protect against fire or radiation. Currently plastering technology is used throughout the Western world, especially in the U.S., Japan, Australia and most Western European countries.

In plastering machines combine three different phenomena, which are very important and key factors in the process of working at plastering machine.

$\circ \quad$ The reason why we begin research in this field are the problems:

- The failure to Work, 
- Unstable system, changing the amount of water ie what changes the composition of the material was then in stages adversely affects job.

- Requires often an employee adjustment of the amount of water in the process.

- The inability to guarantee the sustainability of the material due to unfulfilled conditions in accordance with the requirements of the manufacturer of the material (especially in the Balkan region where working conditions are usually weak).

- When working with material of the same type but the producers change is likely that the humidity that requires the material to have small changes that hardly operator discovers or reveals or shoot only with a separate caution which we routinely works as is she missing machine operator.

- $\quad$ Our goal is to make those kind of machines intelligent.

- Making plastering machine much more precise,

- Making plastering machine useful and easy usable.

- To realize it we have to made e new electronic board which will be conectet by humidity sensor.

- Completion of the requirements for the material guarantee.

Measurements in the laboratory which will be carried out so as to understand what kind of performance is optimal.He will continue in that field measurements until we have enough measurements to achieve much higher level of security in numbers which will get further basic steps.

\section{- Requirements}

Requirements must be specified with measurable parameters -

- Water flow possible be regulated in a smaller unit to 3 liter.

- $\quad$ No need for adjustment of the start up until the end of the job.

- The possibility of regulating the amount of water in the material.

\section{- METHODOLOGY}

Access to the application which we have a long time before begin of the researching is paved in three directions, or better said the study of this request involves three aspects:

1.The financial aspect

2. Sustainability also adapting working conditions.

3. Flexibility for user

\section{The financial aspect}

As far as the financial aspect we will strive solution which will be presented to be in its optimal financial Aspektin financiar. Our proposal will be the acceptable from each client only needs a better explain of the operation and the exact solution, which we offer.With a calculation very quickly reach a positive outcome which justifies the application acceptance in advance of the system.Project which we have managed to secure after a practical working directly with these machines and the next part at the laboratory.

\section{$\circ \quad$ Sustainability and adjustment in working conditions}

Then taking into account the conditions which exposed the machines in question, we will take care that the systemwhich will be presented as a solution to the problem posed, to be well preserved and resistant to detrimental factors and conditions which may affectboth physically and in the process.Electronic part will be ensure the electrical panel inside of the machine. Sensor will be placed in a crib built for which there will be the barrier for the operator but will provide the sens or from damage possible physical or humidity.

\section{- Flexibility for user}

Will develop a manual for the user.Also in this manual will also present additional evidence for maintenance, which will be prepared in the form of professional and accessible for maintenance personnel. Upgrading of the system will be the understandable for each operator with a few minutes of explanation.To realize the measurement of humidity, we had a sensor for measuring the moisture in the material.After searching on the internet we came to the conclusion that we have to think for the construction of a sensor.

\section{○ Piezoelectric Theory}

The piezoelectric effect was discovered by Pierre and Jacques Curie in 1880. It remained a mere curiosity until the1940's. 
A piezoelectric substance is one that produces an electric charge when a mechanical stress is applied (the substance is squeezed or stretched). Conversely, a mechanical deformation (the substance shrinks or expands) is produced when an electric field is applied. This effect is formed in crystals that have no center of symmetry. To explain this, we have to look at the individual molecules that make up the crystal. Each molecule has a polarization, one end is more negatively charged and the other end is positively charged, and is called a dipole. This is a result of the atoms that make up the molecule and the way the molecules are shaped. The polar axis is an imaginary line that runs through the center of both charges on the molecule. In a monocrystal the polar axes of all of the dipoles lie in one direction.

Piezoelectric measuring systems are active electrical systems. That is, the crystals produce an electrical output only when they experience a change in load. For this reason, they cannot perform true static measurements.

\section{- Applications of piezoelectric effect}

Piezoelectric measuring devices are widely used today in the laboratory, on the production floor and as original equipment. They are used in almost every conceivable application requiring accurate measurement and recording

of dynamic changes in mechanical variables such as pressure, force and acceleration.

Pieozoceramics are materials that demonstrate what is known as the piezoelectric effect: Piezoelectric Effect; appearance of an electrical potential across some faces of a crystal when it is under pressure, and of distortion when an electrical field is applied.

The piezoelectric effect can now be observed in the crystal. Figure 3 illustrates the piezoelectric effect. Figure 3a shows the piezoelectric material without a stress or charge

If the material is compressed, then a voltage of the same polarity as the poling voltage will appear between the electrodes (b). If stretched, a voltage of opposite polarity will appear (c). Conversely, if a voltage is applied the material will deform. A voltage with the opposite polarity as the poling voltage will cause the material to expand, (d), and a voltage with the same polarity will cause the material to compress (e). If an AC signal is applied then the material will vibrate at the same frequency as the signal (f).

\section{- Experimental design}

The project requires which we want to reach are some equipment which are quite specific.

Sensor for the measurement of moisture in the material, then a elektromotorr with a very small output speeds, and electronic plate for synchronization all of these processes.

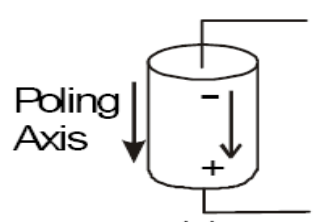

(a)

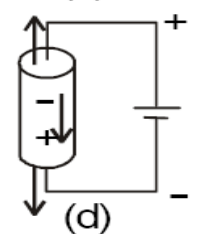

(d)

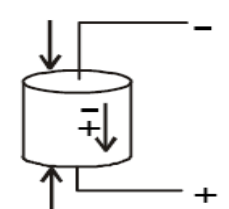

(b)

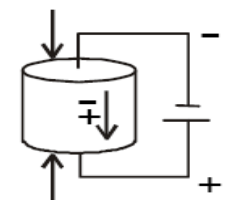

(e)

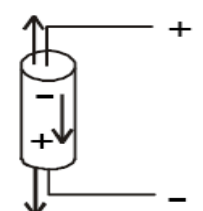

(c)

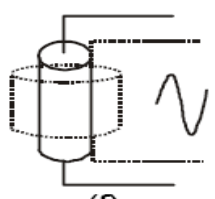

(f)

\section{IV.1Example of Piezoelectric Effect}

1.By exploiting the phenomenon of the electromagnetic field effect, the impact in the change of the environment in which she developed electromagnetic field.

2. Piezosensor with the help of piezoelement which will use a vibration generator and a recipient of the vibrations.

\section{- Electronic board}

But as we know in one of our goals is to choose which we will present should definitely be a thing which the use of economic reasoning PLC comes in great danger mjat. For this reason we have decided that this is accomplished with an electronic tiles which will construct and realize we own.

\section{- Actuator}

Actuatorvill be a electric motor $12 \mathrm{~V}$ Power voltage direct current, $01 \mathrm{~kW}$.

While the ratio of teeth after Reduktor which we found in the market that is 60rpm exit we need a reduction which based on calculations show that is twice teeth contains one ready.

$S_{1} \cdot T_{1}=S_{2} \cdot T_{2} ; \quad T_{2}=\frac{S_{1} \cdot T_{2}}{S_{2}} ; \quad S_{1}=60 \mathrm{rpm} ; T_{1}=12 ; \quad S_{2}=30 \mathrm{rpm} ; T_{2}=\frac{60 \mathrm{rpm} \cdot 12}{30 \mathrm{rpm}} ; \quad T_{2}=\frac{720}{30} ; T_{2}=24$

After emerging from this material is ready for plastering. The humidity of mixed material have to be according the material producer and all of them are based at DIN EN 1880.

\section{- Sensor}

We tried to measure the humidity of material by one self made electromagnetic sensor. 
This type of sensor is performed in the classical form ie are simply pick two metallic plates that are put in alternative voltage of $12 \mathrm{~V}$, and at one end is connected a potenciometer where we attempted to measure the electromagnetic field changes after environmental change between the tiles

After deciding that the abovementioned components in their position we started with measurement during changing water quantity in the material.

However the results were unstable and irregular, we have tried to influence the systemin different ways, but at the end as a conclusion to this form of measurement in this systemwe have that this kind of measurement in this case is not very suitable and not correct

I didn't get the request result so next alternative is to use piezoelement plate.

From our previous knowledge in both theoretical and practical aspects in consultation with superwiser we started to analyze the theory of piezoelectric effect, which we see now days applies in many fields were used in processes where a high precision and quality of work.

Piezoelectric measuring systems are active electrical systems. That is, the crystals produce an electrical output only when they experience a change in load. For this reason, they cannot perform true static measurements.

However, it is a misconception the piezoelectric instruments are suitable for only dynamic measurements.

Quartz transducers, paired with adequate signal conditioners, offer excellent quasistatic measuring capability.

There are countless examples of applications where quartz based sensors accurately and reliably measure uasistatic phenomena for minutes and even hours.

These measurements are made by the oscilloscope. During the beginning of experiment we used flasks which served as a substitute of aluminum tube has been worn in some cases have had different results that we think are noises results that are created by the vibration case, caused by piezoeffet.

Therefore we decided to use a part plastke and also in application care must be taken that the part which is being used the realization of the sensor is plastic

Table 6. Result of mesurment

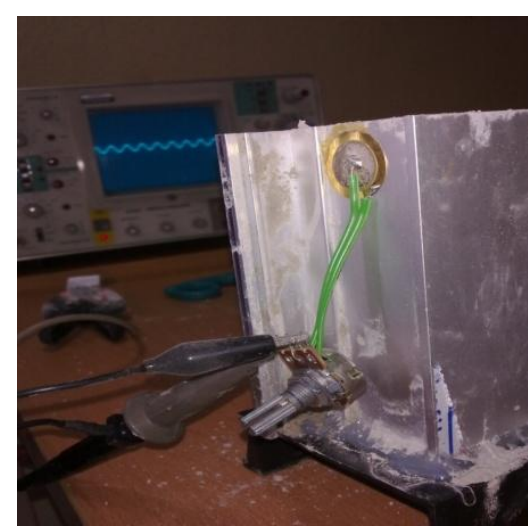

IV.2 Measurements of midresistance

\begin{tabular}{|c|c|c|c|c|c|c|c|c|c|}
\hline 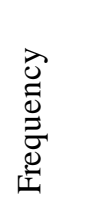 & 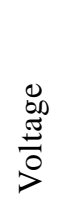 & 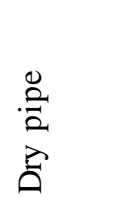 & 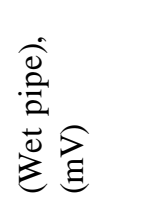 & 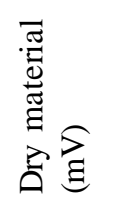 & 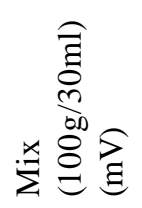 & 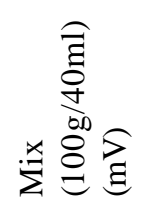 & 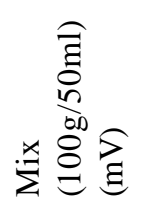 & 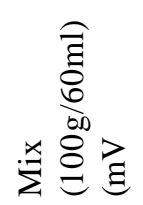 & $\begin{array}{l}\dot{\bar{\Xi}} \\
\stackrel{\vec{\sigma}}{3}\end{array}$ \\
\hline \multirow[t]{2}{*}{$2 \mathrm{kHz}$} & $5 \mathrm{~V}$ & $0.5 \mathrm{mV}$ & $0.4 \mathrm{mV}$ & $0.1 \mathrm{mV}$ & $1 \mathrm{mV}$ & & & & 2 \\
\hline & $9 \mathrm{~V}$ & $0.5 \mathrm{mV}$ & $0.7 \mathrm{mV}$ & $0.3 \mathrm{mV}$ & $1.5 \mathrm{mV}$ & & & & $3.1 \mathrm{mV}$ \\
\hline \multirow[t]{2}{*}{$4 \mathrm{kHz}$} & $5 \mathrm{~V}$ & $1 \mathrm{mV}$ & $2 \mathrm{mV}$ & $0.2 \mathrm{mV}$ & $0.3 \mathrm{mV}$ & & & & $2 \mathrm{mV}$ \\
\hline & $9 \mathrm{~V}$ & $1.5 \mathrm{mV}$ & $3 \mathrm{mV}$ & $0.5 \mathrm{mV}$ & $0.5 \mathrm{mV}$ & $0.5 \mathrm{mV}$ & & & $2.3 \mathrm{mV}$ \\
\hline \multirow[t]{2}{*}{$5 \mathrm{kHz}$} & $5 \mathrm{~V}$ & $5 \mathrm{mV}$ & $2.5 \mathrm{mV}$ & $1 \mathrm{mV}$ & $0.5 \mathrm{mV}$ & $0.5 \mathrm{mV}$ & $0.1 \mathrm{mV}$ & & $0.8 \mathrm{mV}$ \\
\hline & $9 \mathrm{~V}$ & $10.5 \mathrm{mV}$ & $3.5 \mathrm{mV}$ & $1.5 \mathrm{mV}$ & $1 \mathrm{mV}$ & $1.3 \mathrm{mV}$ & $0.3 \mathrm{mV}$ & & $1 \mathrm{mV}$ \\
\hline \multirow[t]{2}{*}{$6 \mathrm{kHz}$} & $5 \mathrm{~V}$ & $3 \mathrm{mV}$ & $2.5 \mathrm{mV}$ & $0.5 \mathrm{mV}$ & $0.2 \mathrm{mV}$ & $0.5 \mathrm{mV}$ & $1.2 \mathrm{mV}$ & $0.2 \mathrm{mV}$ & $2.8 \mathrm{mV}$ \\
\hline & $9 \mathrm{~V}$ & $5 \mathrm{mV}$ & $3 \mathrm{mV}$ & $1 \mathrm{mV}$ & $0.5 \mathrm{mV}$ & $1.4 \mathrm{mV}$ & $2 \mathrm{mV}$ & $0.5 \mathrm{mV}$ & $4.2 \mathrm{mV}$ \\
\hline \multirow[t]{2}{*}{$7 \mathrm{kHz}$} & $5 \mathrm{~V}$ & $6 \mathrm{mV}$ & $1.5 \mathrm{mV}$ & $1 \mathrm{mV}$ & $0.5 \mathrm{mV}$ & $0.7 \mathrm{mV}$ & $0.7 \mathrm{mV}$ & $1.2 \mathrm{mV}$ & $1 \mathrm{mV}$ \\
\hline & $9 \mathrm{~V}$ & $11 \mathrm{mV}$ & $1.8 \mathrm{mV}$ & $2.5 \mathrm{mV}$ & $0.8 \mathrm{mV}$ & $1.7 \mathrm{mV}$ & $1.2 \mathrm{mV}$ & $2 \mathrm{mV}$ & $1.8 \mathrm{mV}$ \\
\hline \multirow[t]{2}{*}{$8 \mathrm{kHz}$} & $5 \mathrm{~V}$ & $3 \mathrm{mV}$ & $3.8 \mathrm{mV}$ & $1 \mathrm{mV}$ & $1.5 \mathrm{mV}$ & $1.5 \mathrm{mV}$ & $1 \mathrm{mV}$ & $0.8 \mathrm{mV}$ & $5.2 \mathrm{mV}$ \\
\hline & $9 \mathrm{~V}$ & $5 \mathrm{mV}$ & $6 \mathrm{mV}$ & $2.5 \mathrm{mV}$ & $2 \mathrm{mV}$ & $2.2 \mathrm{mV}$ & $1.5 \mathrm{mV}$ & $1.1 \mathrm{mV}$ & $10 \mathrm{mV}$ \\
\hline \multirow[t]{2}{*}{$9 \mathrm{kHz}$} & $5 \mathrm{~V}$ & $18 \mathrm{mV}$ & $7 \mathrm{mV}$ & $3.5 \mathrm{mV}$ & $2.5 \mathrm{mV}$ & $2 \mathrm{mV}$ & $2.5 \mathrm{mV}$ & $1.5 \mathrm{mV}$ & $1.8 \mathrm{mV}$ \\
\hline & $9 \mathrm{~V}$ & $26.5 \mathrm{mV}$ & $12.5 \mathrm{mV}$ & $7 \mathrm{mV}$ & $4.5 \mathrm{mV}$ & $4 \mathrm{mV}$ & $4.2 \mathrm{mV}$ & $2.8 \mathrm{mV}$ & $2.5 \mathrm{mV}$ \\
\hline
\end{tabular}

Now we begin the work of building electronic places for the reason that without having well known that we are at the entrance signal frequencies and voltage we can not begin the design of places:

At the entrance of the plate have $9 \mathrm{kHz}$ frequency signal and voltage $9 \mathrm{~V}$.

Choosing electric motor taking into account the place of assembly and power requirements electric motor should be more gavarite small in order not to become stumbling tool while working voltage also which is not a problem in case of contact with water, which voltage is present in electronic plate then use alternate $12 \mathrm{~V}$ voltage.

Investment to be more acceptable in the market will not change at all valve just going to adopt the same system that is used in the valve manual systemengages mototrri and make water flow regulation. 
Valve which in use of the belt $10^{*} 360^{\circ}$ rotation.

Potenciometri which used to convey the state of the valve will be placed on the axis of the valve by means of a wheel where $0 \Omega$ state will be closed while the valve position to $5.7 \mathrm{k} \Omega$ situation will be fully open position.It serves us in the process to be informed all the time about the state of the valve.

Resolution which we have done, facilitates working with these machine unless this increases the precision at work.

Work with these machines is likely to change the flow of water the amount of water flow and this is seen later or not seen at all by the operator.Which appear as obstacles in the following procedure, alignment and smoothing of the surface

With the application of the system presented by us this problem is reduced or eliminated almost entirely.Our systemevery three seconds make a test of the material condition and sends the information on electronic plate, which then decides to increase the level of water flow or reduce it.

Also in case of change of the material systemitself changes the water flow level.

In some cases, material that does not come from the same manufacturer changes the demand for water, depending on the product or product series also here comes in the application of intelligent systemin expression.

Special occasions is when filling sieves of waste as a result we have flow-level reduction. This directly affects the situation of production materilit.The problem is shown more in the Republic of Kosovo where due to dirty water which is used in industry.In the absence of industrial water network used different forms of water supply, use pumps and different gavanoze.Improper care in maintaining water impurity as a result of the lack of qualification of employees to work with plastering machines.Many problems arise also in the process of work plastering machine water system.

In this case our system will eliminate the damage caused by the qualification insufficient by unclean water. Raised questions as by unclean water fragmented that we have not foreseen any form of purification or water filtration specially.

The system will engage that we have always exit with the same humidity output.While it is possible to keep this when the road blocking the water so much that our sisitemi opened up to the maximum valve and again there is a lack of water in the system then it presents alarm pamjatueshem water at the entrance and stop the machine.

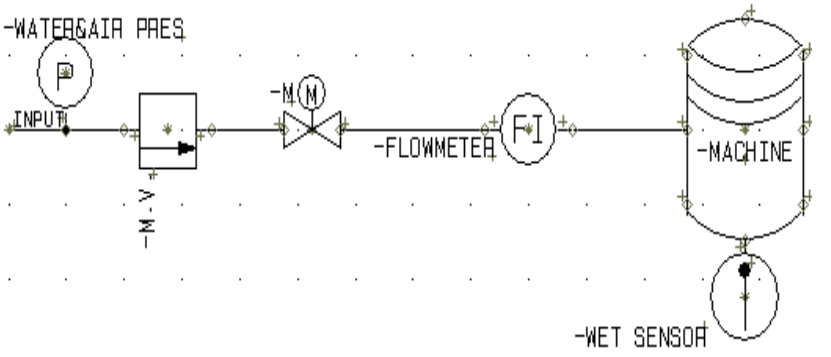

In cases where we use for the first time a material for which

we do not have proper knowledge about the value of water.Then we have no need at all to arrange several times until you reach the optimum because the system will take over themselves this way and regardless What materili we entrance, exit will have the same humidity always.

One thing also required labor standards which specify conditions plastering work.

Electric motor which use as actuator is $0.1 \mathrm{~kW} 1000$ exit rotations. He is using a Reduktor who reduces this number of rotations to a very small number of rotations and a great power.

Activition of electric motor will be on given time. We have not used step motor with whom it would be easy and activation request but accuracy stoppage time in this form that we decided we demand is optimum precision and height of economic level.

\section{RESULTS}

\section{- Results for Experimental Setup}

The second case's final result may present point for which are determined during the measurement, for which think is optimimu and desirable item

During design of electronic board would we care to take into consideration all the factors which may then impact directly or vice versa in the process of work in the machine entirely

Electronic board will be supplied with alternative voltage of $12 \mathrm{~V}$.

Input unit in the tablet will be:

1. Wet sensor

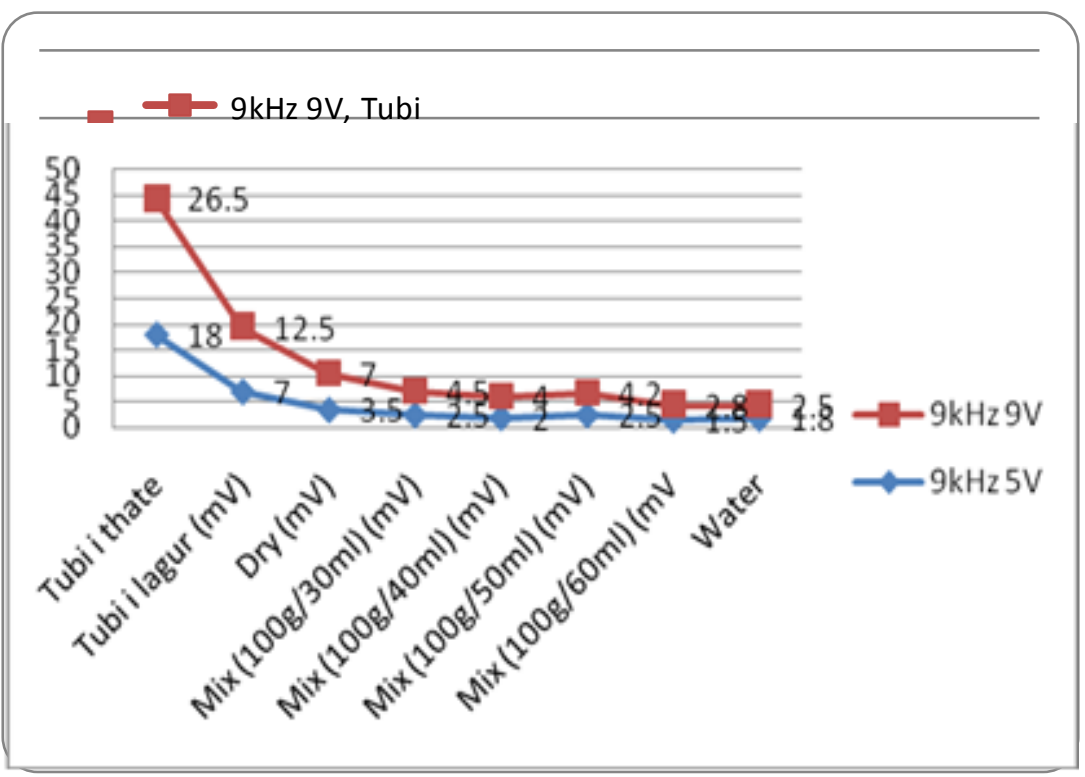


2. Water pressure switch

3. Air pressure switch

4. Selector manual-automatic

5. Buttons in stand potentiometer

6. Potentiometer for valve position Output unit from electronic plate are:

1. Output for sensor

2. Electromotor power supply

3. Supply for potentiometer

4. Output for K1

Labor process for which will take care the electronic plate, changes over time, depending on the load condition and the type of material.

Initial condition is when the mashine is disconectet from the power supply.

1. Insertion of power supply which automatically

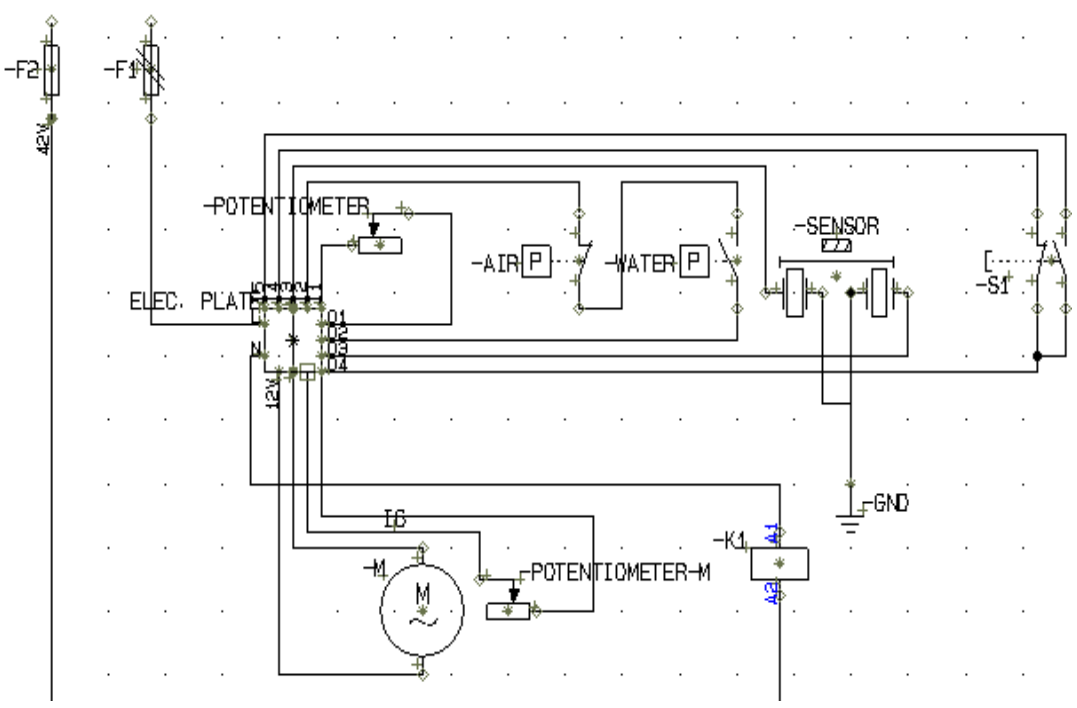
requires the systemto

\section{Electronic board conection}

switch to the starting condition of the original, which requires that the valve be fully open and some time after startup $(\mathrm{t}=5 \mathrm{~s})$ begin state testing material

2. After time $t=5 \mathrm{~s}$ activated sensor which tests the condition of the material and depending on the amount of water in the material, following the process in the opening and closing of the valve.

3. Upon the order of the electronic tiles to move electric motor will make a movemente that would be in proportion $5 \mathrm{~L}$ ie each starte electric motor who commands valve means $\pm 5 \mathrm{~L}$ water in the material.

4. On the occasion when we intermittent water pressure, or intermittent due to air pressure which is the operator desires then the machine will have an interruption

5. a.In this case, the system does not require to return the valve to the starting position. The valve will stay at predetermined position until we have disconnection of electricity power supply which we decided to have as a reset consent.(This can be changed at the request of operators since in some countries such as Kosovo frequent interruptions of electricity and this could present problems).

b.machine will have the option of disconnecting from electric energy through the main breaker, but this case will not have to reset the program since the program supply will be made directly.

$\mathrm{PW}$-is that water pressure created by the pump located in the car's system. 


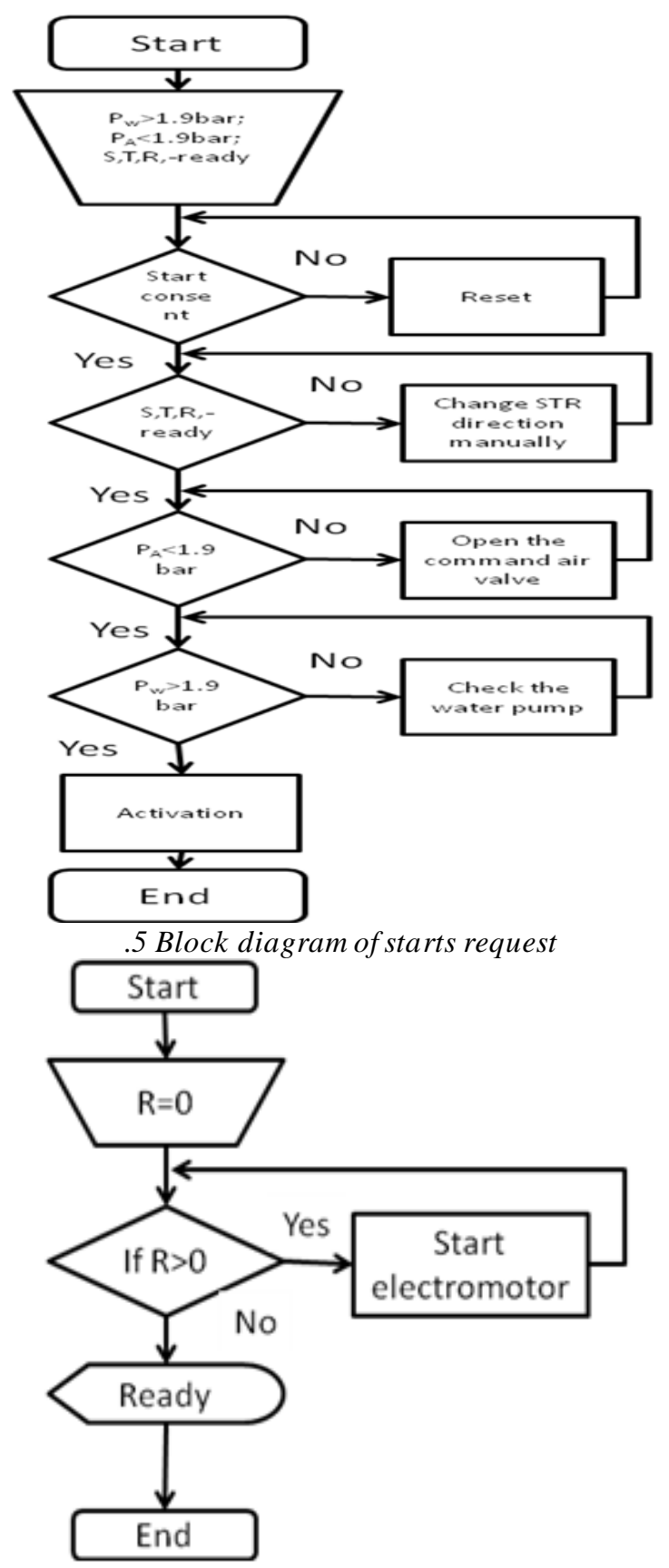

IV.6Block diagram of reset consent

PA is the pressure of compressed air which is created by the compressor with two piston located on the machine system

The first application of the system is reset the system. authentication that has realized actuator valve opening.Has reached the required reset.

The third request is: water pressure which is required to be above 1.9 bar.

Once these requirements are met is ready for starting machine, which happens by suppressing the starter button. Reset control system which we have designed will be implemented in the logic diagram presented here. $\mathrm{R}$ is the resistance of potenciometrit which is located to the valve, which opens and closes from elektromotorri.This opening and closing followed by potenciometri, the following information, which transmitted to the electronic label and know exactly the condition of the valve.

Potenciometrit situation after reset must be in zero.It usually remains in the working position so that after connecting power supply, the system will come to a position where potenciometri is equal to zero.

This diagram is activated after a startup time of the main engine.We were careful not to have the disorder in the work process, since the system is very delicate.If the testing time will begin with the start of the system then we 
will have false information in the entry because that material which is mixed with is not at the same time in output but it requires time.

After start-up of humidity control system must provide the required constant moisture in the material.On the basis of which the system then will keep the same humidity. This constant in the diagram is the value of $\mathrm{k}$ which in our diagram is in milli ampere and for the operator will be pres ented in numerical units.

Possibility of deviation shall be $\pm 3 \mathrm{~L} / \mathrm{h}$.

Ring testing will be activated every 5 seconds for the reas on that When contributing stabilization have no major changes in short time,

On the basis of knowledge about the process of the work of this machine have concluded that the time of $5 \mathrm{~s}$ is sufficient for control.

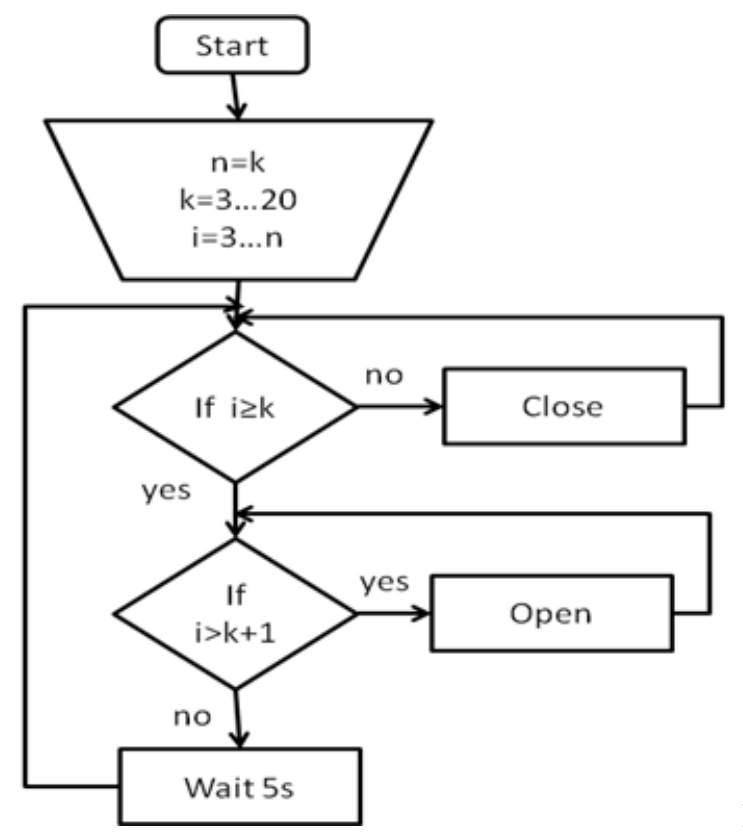

IV

7Block diagram of sens or control

In this diagram shows the order of activation of the components of the machine in case of system activation.

\section{DISCUSSIONS AND CONCLUSION}

In summary for the work until now, it appears that the advancement in these machines is not a simple job, also has a great importance in this field of activity.

Complication comes as a result of the combination of the very nature of physical phenomena in the process of operation of the machine.

Complexity is increased even more by the fact that they are mobile machines which are under the influence of conditions and factors which affect them in different places, for this reason precision which is required in the process is difficult attainable by the human factor.

Now machine for plastering is the smart machine. Now, will not have problems with water supply, that for this looks after our system.

In system which we have worked, we cared that the system even in abnormal cases have concrete solutions and not found in any situation sighted.

In the case when the water blocks the road after passing the pressure switch, our system will make the valve open further to release the amount of water in the process has as necessary to achieve the material moisture which state we have determined, based on technical data of the material manufacturers.

During the work are also displayed other requirements which I have incorporated in the system such as the use 
of different materials which can be used in the machine and have different requirement in terms of quantity water in the material. And in cases of undesirable power outages.

Our system will be the flexible and us able will not add new knowledge requirements for the operator because it is incorporated with an explanation he simply understands the functioning of the machine as a system entirely. By working in this machine emerges another fact, that material moisture measurement mixed.So sensor for measuring moisture to the process of mixing materials which you can use also in the process of production of food in order to have accurate knowledge about the state of matter in production.

The use of this sensor can be done so well in all other processes.In certain cases where the difference is very small then the material would be intervention needs in electronic components increased signal amplifier.

for the purpose of processing information more easily.

To all who want to develop this part of the industry think that there is still much to advance and build precision and to facilitate the work of man who works in the processes that are affected by these machines.

For example the consumables part these machines (schnecke) is not the stated limit of her life request but approximate figures given by manufacturers, usually after the consumption of this schnecke peoples get a dilemma of whether there is a problem in the system or is end of schnecke I think a kind of measure of the amount of material which has produced this schnecke would help to have an operator with the full conviction in the case of submission of these type problems in the machine.

Then mechanical investigation which would affect the facilitation of transfer of this machine from a workshop in another workshop.

\section{- REFERENCES}

DIN 18350 - 2006-10 Putz- und Stuckarbeiten

DIN 18560-1 - 2004 Estriche, Anforderungen

DIN 18560-2 - 2004 Estriche auf Daemmschicht

DIN 18560-3 - 2004 Verbundestriche

DIN 18560-4 - 2004 Estriche auf Trennschicht

DIN EN 13813 - 2003 Estrichmoertel + Estrichmassen

N_264_EN 13279-2_e_stf_2004

BETRIEBSA NLEITUNG PFT G4 Super

http://www.m-tec.com/uk/Baustellentechnik/Maschinen/mischpumpen/m300.php (15.05.2012; 23:30)

http://www.rdmitalia.it/intonacatrice-fast-p-6.html (21.05.2012; 15:30)

http://pdf1.alldatasheet.com/datasheet-pdf/view/159225/STMICROELECTRONICS/TL072.html

Chapter 2 Background 2.1 Piezoelectric Theory 21.06.2012; 10.40

(http://hyperphysics.phy-astr.gsu.edu/hbase/magnetic/magfor.html\#c2 $08.13 .2012,05.03$ )

PZT Aplication manual 